\title{
ANTÍGENO CARCINOEMBRIONÁRIO NO DIAGNÓSTICO DIFERENCIAL DOS DERRAMES PLEURAIS
}

\author{
CARCINOEMBRYONIC ANTIGEN IN DIFFERENTIAL DIAGNOSIS OF PLEURAL \\ EFFUSION
}

\author{
Miguel Angelo Martins de Castro Junior, TCBC- RS'; \\ Nelson Perelman Rosenberg, TCBC - RS'2 ; Ivo Leuck $\mathbf{J r}^{2}$
}

\begin{abstract}
RESUMO: Objetivos: Analisar a sensibilidade e a especificidade da dosagem do CEA no diagnóstico diferencial do derrame pleural de pacientes portadores de doenças benígnas e malígnas. Método: Estudo contemporâneo de série de casos, realizado do Serviço de Cirurgia Torácica do Hospital Nossa Senhora da Conceição, Porto Alegre, Rio Grande do Sul. Entre julho de 2000 e julho de 2001, 64 pacientes foram submetidos à investigação etiológica de efusão pleural,e submetidos aos seguintes exames: pH, LDH, dosagem protêica, densidade, glicose, citologia diferencial, pesquisa de fungos e BAAR, gram e cultura com antibiograma, citopatologia, dosagem de CEA e biópsia pleural. Resultados: Pacientes com derrames de etiologia maligna $(n=26)$ tiveram resultado do CEA variando de zero a $5000 \mathrm{ng} / \mathrm{ml}$, enquanto nos de etiologia benígna os valores variaram de zero a 4,8ng/ml. Nível médio de CEA na efusão carcinomatosa foi de $431 \pm 1237 \mathrm{ng} / \mathrm{ml}$ (média \pm desvio padrão), significativamente maior que nos benignos $(1,1 \pm 1,0 \mathrm{ng} / \mathrm{ml}$; $\mathrm{p}<0,001)$. A sensibilidade, para um ponto de corte de $5 \mathrm{ng} / \mathrm{ml}$, foi de $61,5 \%$ e a especificidade de $100 \%$. Conclusão: Em pacientes com efusão pleural, quando investigados do ponto de vista etiológico, a dosagem do CEA pode ser útil para critério diagnóstico (Rev. Col. Bras. Cir. 2005; 32(1): 15-17).
\end{abstract}

Descritores: Antígeno carcinoembrionário; Derrame pleural; Carcinoma; Marcadores biológicos de tumor

\section{INTRODUÇÃO}

O derrame pleural é um achado clínico importante, e freqüentemente um problema diagnóstico que permanece sem solução mesmo com a avaliação clínica e laboratorial ${ }^{1}$. O seu diagnóstico nem sempre é obtido através do estudo do líquido e/ou da biópsia da pleura parietal, pois em alguns pacientes com doença maligna, apenas a pleura visceral pode estar envolvida e, por outro lado, o acometimento do folheto parietal é freqüentemente multifocal ${ }^{2}$.

Dosagem do Antígeno Carcinoembrionário (CEA) e outras análises bioquímicas, tem sido feitas em efusões pleurais, na tentativa de identificar marcadores tumorais que poderiam discriminar etiologia benigna e maligna ${ }^{3}$. Muitos autores sugerem que a avaliação de alguns produtos tumorais pode ser considerada tanto no soro como no líquido pleural de pacientes com suspeita de derrame pleural maligno ${ }^{2}$. Uma série de estudos histoquímicos destaca o valor de diversos marcadores tumorais como o antígeno carcinoembrionário (CEA), gonadotrofina coriônica humana(hCG), antígeno carboidratado 50(CA-50), antígeno carboidratado 19-9(CA 199), proteína ácida imunossupressiva (IAP), antígeno poliptídeo tissular(TPA) e CYFRA 21-1, entre outros ${ }^{2,4-6}$. Na suspeita de neoplasia, tais marcadores podem sugerir a etiologia maligna do derrame pleural. A avaliação da concentração do CEA é a que tem sido mais usada, talvez por ser tratar de um método acessível. No entanto, os resultados encontrados são bastante variáveis, o que levou alguns autores a questionar o seu valor ${ }^{2}$.
O presente estudo tem o objetivo de analisar a sensibilidade e a especificidade da dosagem do CEA no diagnóstico diferencial do derrame pleural de pacientes portadores de doenças benignas e malígnas.

\section{MÉTODO}

De julho de 2000 a julho de 2001, 64 pacientes portadores de derrame pleural foram submetidos à investigação através de exames do líquido pleural: pH, DHL, proteínas, densidade, glicose, citologia diferencial, cultura bacteriana, pesquisa de fungos e BAAR, citopatologia e determinação do CEA. Foi também realizada biópsia da pleura com agulha de Cope e análise histológica. O CEA foi dosado no líquido pleural através de kit imunoenzimático.

O derrame pleural era considerado maligno quando um dos seguintes critérios era preenchido: (1) demonstração de células malignas à avaliação citológica ou na biópsia pleural; (2) malignidade primária comprovada histologicamente, com exclusão de qualquer outra causa conhecida de derrame pleural, como, tuberculose, infecção pulmonar, pancreatite, insuficiência cardíaca congestiva etc.

Os valores do CEA foram considerados normais até $5 \mathrm{ng} / \mathrm{ml}^{2}$.

Os dados foram previamente armazenados e depois analisados através do programa Epi Info 6.04b. São demonstrados em média ou em percentagem quando indicados. Resultados do CEA para classificar os derrames pleurais como malignos ou benignos foram analisados quanto à sensibilida-

1. Cirurgião Torácico (TE CBC); Professor do Departamento de Cirurgia, Fundação Universidade Federal do Rio Grande - FURG, Rio Grande, RS.

2. Cirurgião Torácico (TE SBCT); Hospital Nossa Senhora da Conceição, Porto Alegre, RS.

Recebido em 08/06/2004

Aceito para publicação em 10/09/2004

Trabalho Realizado no Hospital Nossa Senhora da Conceição, Grupo Hospitalar Conceição, Porto Alegre, RS. 
Tabela 1 - Distribuição etiológica do grupo benigno.

\begin{tabular}{lrc}
\hline Grupo Benigno n=38 $\mathbf{( 5 9 . 4 \% )}$ & $\mathbf{n}$ & $\mathbf{\%}$ \\
\hline Tuberculose & 23 & 61 \\
Parapneumônico & 7 & 19 \\
Insuficiência Cardíaca & 3 & 7,5 \\
Processo Inflamatório Intra-abdominal & 1 & 2,5 \\
Ascite & 1 & 2,5 \\
Síndrome Veia Cava Superior & 1 & 2,5 \\
Insuficiência Renal Crônica & 1 & 2,5 \\
Atelectasia & 1 & 2,5 \\
\hline
\end{tabular}

de e especificidade. Os resultados dos dois grupos foram então comparados por teste não paramétrico Mann-Whitney para variáveis contínuas e teste $\chi^{2}$ para variáveis não contínuas.

\section{RESULTADOS}

A etiologia dos derrames pleurais benignos e malignos encontra-se nas Tabelas 1 e 2.

Pacientes com diagnóstico etiológico de malignidade $(n=26)$, apresentaram resultados de CEA que variaram de zero a $5000 \mathrm{ng} / \mathrm{ml}$, enquanto que os casos benignos alcançaram níveis de zero a $4,8 \mathrm{ng} / \mathrm{ml}$. Nenhum paciente com derrame pleural benigno ultrapassou $5 \mathrm{ng} / \mathrm{ml}$ de CEA. Em contrapartida, 10 pacientes $(38,5 \%)$ com doença comprovadamente maligna não ultrapassaram o ponto de corte. Estes foram: dois casos de neoplasia pulmonar (sendo um de grande células) e oito casos de doença pleural por neoplasia à distância (dois linfomas mediastinais com comprometimento pleural, dois carcinomas de mama, um carcinoma de pâncreas, um carcinoma papilar de epiploon, um caso de melanoma e um de tumor de mediastino de células germinativas).

O nível do CEA em fluídos malignos foi de $431 \pm 1237$ $\mathrm{ng} / \mathrm{ml}$ (média \pm desvio padrão) significativamente maior que fluídos benignos $(1,1 \pm 1,0 \mathrm{ng} / \mathrm{ml} ; \mathrm{p}<0,001)$.

Os níveis de CEA para pacientes com câncer de pulmão e com outras neoplasias foram $637 \pm 1640$ e $322 \pm 1005$ ng/ $\mathrm{ml}$, respectivamente. Estes níveis foram também significativamente diferentes entre os grupos com câncer de pulmão e os pacientes com doença benigna, e entre pacientes com outras neoplasias e os pacientes com doença benigna de acordo com o teste $\chi^{2}(\mathrm{p}<0,005)$.

A sensibilidade, quando se utilizou ponto de corte de $5 \mathrm{ng} / \mathrm{ml}$ foi de $61,5 \%$ e a especificidade de $100 \%$. O limite de $10 \mathrm{ng} / \mathrm{ml}$, utilizado em alguns trabalhos, reduziu a sensibilidade para $57,7 \%$ em nosso estudo mas manteve a mesma especificidade.

A sensibilidade da citologia foi de $34 \%$ e da biópsia pleural alcançou $74 \%$.

\section{DISCUSSÃO}

O CEA é uma glicoproteína aparentemente produzida pela célula neoplásica e costuma estar associado aos carcinomas do tubo digestivo, mama e pulmão, que comumente metastatizam para pleura. Já o mesotelioma pleural raramente cursa com o aumento do CEA no líquido, sendo esta dosagem bastante útil para diferenciá-lo dos adenocarcinomas metastáticos ${ }^{2}$.

Com propósito de diferenciação de efusão pleural, o CEA tem sido usado largamente como marcador tumoral ${ }^{3}$. O ponto de corte dos níveis de CEA para separação entre etiologia benigna e maligna varia de série para série, de $2.5 \mathrm{a} 20 \mathrm{ng} / \mathrm{ml}^{1-6}$. Em 34 a 88\% dos derrames pleurais malignos o CEA está aumentado ${ }^{3}$. Estes valores tendem a aumentar quando a origem dos tumores é o trato gastrintestinal, pulmão ou mama ${ }^{3}$.

A positividade da biópsia no derrame pleural de origem neoplásica pode variar de 40 a $77 \%$, enquanto que o estudo citológico do líquido oferece um reconhecimento diagnóstico que oscila, entre 40 e $87 \%{ }^{2}$. No nosso estudo, a sensibilidade da citologia ficou abaixo da média da literatura, mas em contrapartida a histopatologia da biópsia pleural apresentou bons resultados.

Paganuzzi ${ }^{7}$ pesquisou o valor do CEA e CYFRA 21-1 no diagnóstico de derrame pleural por carcinoma e mesotelioma. O CEA apresentou sensibilidade menor que em outros estudos, 30,6\% para efusão maligna e 52,5\% só no grupo carcinoma. Estes resultados talvez possam ser atribuídos à influência da grande prevalência de mesoteliomas em relação aos carcinomas neste estudo, onde somente um caso de mesotelioma apresentou CEA acima do ponto de corte $(5 \mathrm{ng} / \mathrm{ml})$. A sensibilidade do CYFRA 21-1 também foi significativamente maior em pacientes com mesoteliomas que nos casos de carcinomas.

Moriwaki ${ }^{8}$ estudou grupos distintos de etiologia neoplásica e tuberculosa, concluindo que o nível de CEA foi significativamente maior em derrames carcinomatosos que nos tuberculosos, com sensibilidade de $53 \%$ e especificidade de $100 \%$.

Traczyk $^{1}$ demonstrou concentrações aumentadas de CEA em apenas $37 \%$ dos derrames malignos. Já Niwa ${ }^{9}$ utilizando ponto de corte para determinação de CEA no líquido pleural de $5 \mathrm{ng} / \mathrm{ml}$, obteve sensibilidade de $69,7 \%$ e especificidade de $100 \%$.

No estudo de Miranda ${ }^{2}$, o grupo formado por derrame pleural de origem neoplásica apresentou-se com CEA aumentado em 53\% e apenas um caso do grupo controle (casos não carcinomatosos) teve índice alterado. $\mathrm{O}$ estudo alcançou sensibilidade de $53 \%$ e $95 \%$ de especificidade.

Tabela 2 - Distribuição etiológica do grupo maligno.

\begin{tabular}{lcc}
\hline Grupo maligno n= 26 (40.6\%) & n & \% \\
\hline Carcinoma Pulmonar & $\mathbf{9}$ & $\mathbf{3 5}$ \\
Adenocarcinoma & 4 & 45 \\
Epidermóide & 2 & 22 \\
Grande Células & 1 & 11 \\
Outros & 2 & 22 \\
Carcinoma Metastático & $\mathbf{1 7}$ & $\mathbf{6 5}$ \\
Carcinoma de Mama & 10 & 58 \\
Carcinoma Pancreas & 1 & 6 \\
Carcinoma Gástrico & 1 & 6 \\
Carcinoma Papilar Epiploon & 1 & 6 \\
Melanoma & 1 & 6 \\
Linfoma Mediastinal & 2 & 6 \\
Tumor Células Germinativas & 1 & \\
\hline
\end{tabular}


Vladutiu ${ }^{10}$ chegou à especificidade de $95 \%$ na determinação do CEA em derrames neoplásicos, porém com sensibilidade de apenas $36 \%$.

Diferentemente de nossos resultados, GarciaPauchon ${ }^{11}$ obteve em $9 \%$ dos derrames pleurais não malignos níveis de CEA aumentado.Tem sido descrito que este aumento é mais comum em derrames pleurais por pleurisia, principalmente empiema e derrame parapneumônico.

Tamura $^{12}$ obteve sensibilidade de $50 \%$ e especificidade de $90 \%$ nos derrames pleurais em seu estudo. A conclusão de seu trabalho cita a determinação combinada do CEA e da citologia como úteis no diagnóstico diferencial das efusões pleurais.

Light ${ }^{6}$ sugere que dosagens de CEA no líquido pleural acima de $10 \mathrm{ng} / \mathrm{ml}$ são altamente sugestivas, porém não diagnósticas de derrame pleural maligno. Devido aos resultados falsos positivos, sua dosagem rotineira não estaria indicada, e a citologia, a coloração imuno-histoquímica e a biópsia pleural proporcionam uma resposta mais definida. Cita também que quando o CEA é alto a citologia já é positiva, e em apenas pequeno número de casos a dosagem ultrapassaria a $20 \mathrm{ng} / \mathrm{ml}$ em derrame pleural maligno com citologia negativa. No nosso estudo, dos 26 casos do grupo maligno, nove pacientes apresentaram citologia positiva, sendo quatro com dosagem de CEA abaixo de 20ng/ml, e destes, dois casos abaixo do limite de corte de 5ng/ml. Nos 17 casos com citologia negativa, 11 tinham com dosagem abaixo de $20 \mathrm{ng} / \mathrm{ml}$, e deste, oito casos abaixo do limite de corte de $5 \mathrm{ng} / \mathrm{ml}$.

Os nossos resultados demonstraram que pacientes com citologia negativa, e levando-se em consideração que em alguns serviços a biópsia pleural não é indicada ou não é feita numa primeira abordagem, a dosagem do CEA trouxe um incremento em torno de $50 \%$ na suspeita diagnóstica quando exames de rotina falharam, ou melhor, não tinham ainda se tornado positivo.

Devido a estes aspectos consideramos que a dosagem do CEA no líquido pleural de pacientes submetidos à toracocentese diagnóstica deva ser encarada, não como exame de exceção, mas se tornar solicitação rotineira.

\begin{abstract}
Background: To analyze patients with diagnosis of benign or malignant diseases, in whose evolution develop pleural effusion, in which CEA measurement was questioned in relation to sensitivity and specificity in the differentiation of these two groups. Methods: Prospective consecutive case series of the Department of Thoracic Surgery, Conceição Hospital, Porto Alegre, Brazil. From July 2000 to December 2001, 64 patients were subjected to clinical investigation in search for a pleural effusion aetiology. All patients underwent the following laboratory evaluation of pleural fluid: $\mathrm{pH}, \mathrm{LDH}$, proteins, density, glucose, differential cytology, bacterial culture, search for fungus and acid-fast bacilli, cytology, CEA determination and pleural biopsy. Results: Patients with malignant etiologic diagnosis $(n=26)$, had CEA results ranging from zero to $5000 \mathrm{ng} /$ $\mathrm{ml}$, while benign cases results were from zero to $4.8 \mathrm{ng} / \mathrm{ml}$. CEA level in malignant fluids was of $431 \pm 1237 \mathrm{ng} / \mathrm{ml}(\mathrm{mean} \pm$ $\mathrm{SE})$, significantly higher than benign fluids $(1.1 \pm 1.0 \mathrm{ng} / \mathrm{ml} ; \mathrm{p}<0.001)$. Sensitivity, for a cut-off of $5 \mathrm{ng} / \mathrm{ml}$, was $61.5 \%$ and specificity of 100\%.Conclusions: We conclude that for patients with pleural effusion, CEA concentrations may represent an useful criteria to diagnosis.
\end{abstract}

Key words: Carcinoembryonic antigen; Pleural effusion; pleural malignancy; tumour marker.

\section{REFERÊNCIAS}

1. Satoh H, Sumi M, Yagyu H, et al. - Clinical evaluation of CYFRA 21-1 in malignant pleural fluids. Oncology, 1995,52 (3):211214.

2. Miranda S, Chibante AMS, Dias RM - Valor da dosagem do antígeno carcinoembrionário no diagnóstico diferencial dos derrames pleurais. Pulmão RJ, 1996,2(2):78-80.

3. Martinez-Vea A, Gatell JM, Segura F, et al. - Diagnostic value of tumoral markers in serous effusion: carcinoembryonic antigen, alpha1-acidglycoprotein, alpha-fetoprotein, phosphohexose isomerase, and beta 2-microglobulin.. Cancer, 1982,50(9):17831788.

4. Lai RS, Hsu HK, Lu JY, et al. - CYFRA 21-1 enzyme-linked immunosorbent assay. Evaluation as a tumor marker in nonsmall cell lung cancer. Chest, 1996,109(4):995-1000.

5. Light RW - A new classification of parapneumonic effusions and empyema. Chest, 1995,108(2):299-301.

6. Light RW - Parapneumonic effusions and empyema. In Light RW (ed) - Pleural Diseases. $3^{\text {th }}$ Edition. Baltimore. Willians \& Wilkins, 1995, pp. 129-153.

7. Paganuzzi M, Onetto M, Marroni P, et al. - Diagnostic value of CYFRA 21-1 tumor marker and CEA in pleural effusion due to mesothelioma. Chest, 2001, 119(4):1138-1142.
8. Moriwaki Y, Kohjiro N, Itoh M, et al. - Discrimination of tuberculous from carcinimatous pleural effusion by biochemical markers: adenosine deaminase, lysozime, fibronectin and carcinoembryonic antigen. Jpn J Med, 1989, 28(4):478-484.

9. Niwa Y, Kishimoto H, Shimokata K - Carcinomatous and tuberculous pleural effusions. Comparison of tumor markers. Chest, 1985,87(3):351-355.

10. Vladutiu AO, Brason FW, Adler RH - Differential diagnosis of pleural effusions. Clinical usefulness of cell marker quantitation. Chest,1981,79(3):297-301.

11. Garcia-Pachon E, Padilla-Navas I, Dosda MD, et al. - Elevated level of carcinoembryonic antigen in nonmalignant pleural effusions. Chest,1997, 111(3):643-647.

12. Tamura S, Nishigaki T, Moriwaki Y, et al. - Tumors markers in pleural effusion diagnosis. Cancer, 1988, 61(2):298-302.

Endereço correspondência:

Miguel Angelo M. de Castro Junior

Rua Gomes Freire 741-B, Bairro Centro

96200-470 -Rio Grande- RS

Tel: 053-2316215

E-mail:miguelacjr@hotmail.com 